\title{
Comentario al libro "En búsqueda de esperanza: migración ngäbe en Costa Rica y su impacto en la juventud”, de José Alberto Idiáquez, S.J.
}

\section{Como extranjeros en tierra propia...}

\section{Jorge Sarsaneda del Cid}

Panamá, 210313/David, 290513

En Panamá hay un profesor que aparece como 'analista político' en programas televisivos y habla diariamente por radio. Él dice que las Comarcas no deberían existir porque son un Estado dentro de otro Estado y eso es ilegal. También hay muchos panameños que piensan de esta manera errónea. Quiero pensar que es un punto de vista producto de la ignorancia y no del racismo.

Para la presentación de este libro de José Alberto Idiáquez Guevara, S.J., he pensado solamente tocar un punto que me parece vital y tiene mucho que ver con el tema: la Comarca y su sentido.

La migración del pueblo ngäbe a Costa Rica no es un fenómeno reciente. Hay varios estudios sobre el tema y algunos la sitúan a inicios del año 1900 (Borge, 2006, pp. 8-13; Young, 2009, pp. 7-12; Bozzoli de W., 1974, pp. 381-418). Aunque los ngäbe no hayan vivido en el territorio costarricense del Pacífico en los siglos anteriores, sus antepasados sí lo hicieron. Algunos arqueólogos hablan del Gran Chiriquí cuando se refieren al área de Chiriquí y la región colindante de lo que actualmente es Costa Rica. En los diferentes medios de comunicación social del país se afirma con frecuencia que la población ngäbe no está en un "solo lugar", que les "gusta emigrar"; y otro público, de manera despectiva, se atreve a afirmar que son "vagos y que no les gusta trabajar". Ambos grupos muestran una total falta de conocimiento de la cultura y de la historia del pueblo ngäbe; y el segundo grupo, deja claro que lleva en los poros los estereotipos y prejuicios raciales hacia los indígenas ngäbe.

Es lo que se dice en una de las páginas iniciales del capítulo III del libro que estamos presentando. Sin embargo, sabemos que nadie emigra de su tierra, ni siquiera temporalmente, por placer, o por gusto, o por aburrimiento, lo hace por necesidad. Es lo que les sucede a muchos hermanos ngäbe y buglé de la Comarca. 
En este libro se ha tratado de presentar, con delicadeza, con profundidad, con amplitud, con cariño, esta situación.

Varios investigadores sostienen que los datos arqueológicos, lingüísticos, etnohistóricos y etnográficos de los grupos indígenas que vivieron en la región central y occidental de Panamá, previo y posterior a la conquista permiten ver la continuidad socio-cultural con los ngäbe actuales. Lejos de ser refugiados o marginados, los guaymíes actuales están donde sus antepasados estaban, tanto al este, como al oeste del río Tabasará. Los datos nos indican que, en una y otra forma, son descendientes de la población precolombina; y en consecuencia, tienen derechos históricos plenamente justificados a los territorios donde actualmente se encuentran (Cooke, 1986, pp. 33-56).

Partiendo de esa reflexión etnohistórica, veamos por qué la gente emigra si tiene "tanta tierra" -como dicen algunos- y no la usan.

En el libro se dan varias razones -históricas, geográficas, económicas, sociales, étnicas- que explican la migración temporal de miles de indígenas ngäbe a Costa Rica, todos los años. Sin embargo, creo que hay una razón fundamental que explica mucho de este trasiego humano: la falta de voluntad política de los gobiernos para resolver el llamado "problema indígena".

Como sabemos, en 1997 se definió legalmente la llamada "comarca NgöbeBuglé”. No fue la mejor ni la más beneficiosa definición, pero fue la que se pudo lograr. Muchas comunidades ngäbe y buglé quedaron 'fuera' de la Comarca. Los terratenientes de los distritos de Santa Fe, Tolé, Cañazas y Las Palmas, los extranjeros del archipiélago y la costa de Bocas, las transnacionales de la zona de Riscó, los de la Ganadera Bocas, todos ellos fueron beneficiados con las tierras que no se le reconocieron a los pueblos ngäbe y buglé y hoy estamos sufriendo las consecuencias.

En la Ley 10 (de la Comarca) se incluyó un artículo (el 46) que habla de la creación de una "Comisión, al más alto nivel, para la planificación y promoción del desarrollo integral de la Comarca”. Además, en otros artículos se habla de respeto por la cultura, reconocimiento del idioma, de educación intercultural bilingüe, etc.

Han pasado quince años, muchas protestas, varios asesinados por la fuerza pública, montañas de papeles, multitud de acuerdos y apenas en 2012 se intentó la creación de dicha Comisión, hubo dos reuniones y... todo quedó en nada, para variar. ¿Conclusión? Lo dicho: no hay voluntad política de los gobiernos por dicho desarrollo.

\section{Desarrollo integral de la Comarca: ¿qué es, cómo puede ser, hacia dónde caminar?}

Como muy bien se expresa en el libro:

El pueblo ngäbe, como todos los pueblos indígenas, concibe el territorio como un referente espacial de la identidad étnica. Como espacio histórico, encarna los lazos afectivos con el pasado ancestral, en el que se han consolidado las huellas que dejan las relaciones entre los miembros de la etnia. En su dimensión cultural, el territorio se convierte en el principal referente simbólico de la relación con la madre naturaleza; y al mismo tiempo, es la memoria colectiva que posibilita la reproducción cultural del pueblo ngäbe. Desde el aspecto político el territorio o la 
Comarca constituye un espacio de autogestión, de relaciones de poder, movilización social y reivindicaciones étnicas. Desde lo económico es un espacio de apropiación. Se constituye en la fuente de bienes y recursos del individuo y la etnia, sujeto a diversas formas de ocupación, producción y transformación.

Este párrafo (capítulo V) nos resume lo que significa la Comarca, más allá de una delimitación físico-política. Sin embargo, como todo grupo humano, los pueblos ngäbe y buglé son grupos dinámicos, se desarrollan, buscan 'más allá'. No se pueden quedar 'quietos' en la tierra. Aquí ubicamos lo que dice el artículo 46 de la Ley de la Comarca.

\section{¿Qué debería tener en cuenta dicho "desarrollo integral"?}

Con una población en un $90 \%$ bajo los niveles de la pobreza, parecería que está todo por hacer, sin embargo señalo solamente cuatro puntos que me parecen fundamentales. En otro lugar he desarrollado más este tema (ver "La Ruta de la Desolación”, 2010), aquí solamente haré enunciados:

- $\quad$ En primer lugar, la seguridad alimentaria. Es lo primero y fundamental. La disponibilidad alimentaria suficiente y estable es un requisito indispensable del desarrollo. Hay que tener en cuenta la producción sobre todo de las plantas autóctonas, el mejoramiento de suelos, la reforestación, la cría de animales, la recuperación de la sabiduría ancestral sobre alimentos y manejo de la naturaleza, el intercambio entre las comunidades...

- $\quad$ En segundo lugar, muy unido con lo anterior va el desarrollo de la cultura propia. Tienen que darse las condiciones -dentro de la Comarca- para que el pueblo conozca, promueva y desarrolle su cultura. Esto implica educación intercultural bilingüe, organización, ciertos niveles de autonomía...

- En tercer lugar, la salud integral. No la imposición de un sistema extraño que receta medicinas químicas, impone criterios y desconoce la riqueza secular de la medicina tradicional.

- $\quad$ En cuarto lugar, la organización comunitaria. ¡Fuera los partidos políticos que lo único que han hecho es dividir al pueblo, contaminarlo, desorientarlo, envenenarlo! Es fundamental que se desarrolle la propia organización que se basa en el consenso, en el respeto a los mayores, en la relación fundamental con la tierra.

Si se dan esas cuatro condiciones fundamentales, todo lo demás se hará por añadidura: infraestructura, turismo, proyectos, viviendas, escuelas, etc. Tenemos muchos documentos (Declaración de la ONU sobre Pueblos Indígenas, Convenios 107 y 169 de la OIT, Declaraciones de Kimberley -Sudáfrica, 2002- y Belem -Brasil, 2009-, etc.) que avalan e impulsan estas exigencias, el problema es el de siempre: la voluntad política.

Las sugerencias que hemos hechovan dirigidas sobre todo a hacer de la Comarca un lugar en el que la gente quiera vivir, estar, desarrollarse, producir, celebrar, gozar y terminar su vida. Que la migración no sea una tentación permanente o una necesidad vital sino, a lo sumo, una posibilidad extrema. Que este libro nos ayude en esta tarea o ¿debería decir, utopía? 